\title{
Activity at Injection Site
}

National Cancer Institute

\section{Source}

National Cancer Institute. Activity at Injection Site. NCI Thesaurus. Code C87023.

An artifact resulting from excess signal at the injection site. 